\title{
Synthesis of 7-aryl(alkyl)1,2,4-triazolo[1,5-a]pyrimidine Using Conventional Methods
}

\section{Elisandra Scapin*, Lilian Buriol, Taiana Scalco München, Clarissa Piccinin Frizzo, Mara Marzari, Marcos A. P. Martins}

\section{*scapin@uft.edu.br}

Keywords: Triazolopyrimidine, 3-amino-1,2,4-triazole, cyclocondensation reactions

\section{INTRODUCTION}

The chemistry of 1,2,4-triazolo[1,5-a]pyrimidine derivatives has been of considerable interest of medicinal and agricultural chemistry for many years ${ }^{1}$. Two very important herbicides, Flumetsulam and Metosulam show acetohydroxyacid synthase inhibitor properties ${ }^{2}$. Other $[1,2,4]$-triazolo[1,5a]pyrimidines with antiparasitic, antimicrobial ${ }^{3}$ and anticancer $^{4}$ activities also are documented. The more related route to 1,2,4-triazolo[1,5-a]pyrimidine is by use of unsymmetrical vinylogous iminium salts ${ }^{5}$. Other route know-well are cyclocondensation reactions of aminoazoles with, $\alpha, \beta$-unsaturated ketoesters and aldehydes in multicomponent reactions ${ }^{6}$. In this context, the objective of this work is synthetized 7-aryl(alkyl)1,2,4-triazolo[1,5a]pyrimidine from ciclocondensation reaction of $\beta$ dimethylaminovinyl ketones and 3-amino-1,2,4triazole.

\section{RESULTS AND DISCUSSION}

The 1,2,4-triazolo[1,5-a]pyrimidine 3a-m were prepared from ciclocondensation reaction between the corresponding $\beta$-dimethylaminovinyl ketones 1am (1.0 mmol) and 3-amino-1,2,4-triazole 2 (1.0 $\mathrm{mmol})$ in acid acetic $(5 \mathrm{~mL})$ under reflux during 24 hours (Figure 1). After the reaction time the solvent was removed under reduced pressure. The products were extracted with dichloromethane $(5 \mathrm{~mL})$, washed with water $(3 \times 5 \mathrm{~mL})$ and dried on magnesium sulfate.<smiles>[R1]c1ccnc2ncnn12</smiles>

$i=$ acid acetic, $118^{\circ} \mathrm{C}, 24 \mathrm{~h}$.

Figure 1. Synthesis of 7-aryl(alkyl)1,2,4-triazolo[1,5a]pyrimidine 3a-m

The products were obtained with moderate to good yields at a high degree of purity and without additional step of purification (Table 1). The structure of 1,2,4-triazolo[1,5-a]pyrimidines were determined by spectroscopy of ${ }^{1} \mathrm{H},{ }^{13} \mathrm{C}$ NMR and $\mathrm{X}$ ray diffraction.

Table 1. Yields of 7-aryl(alkyl)1,2,4-triazolo[1,5a]pyrimidine $3 \mathbf{a}-\mathbf{m}$.

\begin{tabular}{|c|c|c|}
\hline Product & $\mathrm{R}^{1}$ & yields ${ }^{a}(\%)$ \\
\hline $3 a$ & $\mathrm{CH}(\mathrm{OMe})_{2}$ & 63 \\
\hline $3 b$ & $\mathrm{CCl}_{3}$ & 83 \\
\hline $3 c$ & $\mathrm{CF}_{3}$ & 73 \\
\hline $3 d$ & $\mathrm{Ph}$ & 61 \\
\hline $3 e$ & $\mathrm{Ph}-\mathrm{Ph}$ & 89 \\
\hline $3 f$ & $4-\mathrm{F}-\mathrm{C}_{6} \mathrm{H}_{4}$ & 69 \\
\hline $3 g$ & $4-\mathrm{Br}-\mathrm{C}_{6} \mathrm{H}_{4}$ & 78 \\
\hline $3 h$ & 4-I- $\mathrm{C}_{6} \mathrm{H}_{4}$ & 85 \\
\hline $3 \mathbf{i}$ & Tien-2-il & 75 \\
\hline 3j & Pirrol-2-il & 55 \\
\hline 31 & $4-\mathrm{OMe}-\mathrm{C}_{6} \mathrm{H}_{4}$ & 71 \\
\hline $3 m$ & $4-\mathrm{NO}_{2}-\mathrm{C}_{6} \mathrm{H}_{4}$ & 87 \\
\hline
\end{tabular}

${ }^{\mathrm{a} Y i e l d ~ o f ~ i s o l a t e d ~ p r o d u c t . ~}$

\section{CONCLUSION}

In summary, the synthesis of 7-aryl(alkyl)1,2,4triazolo[1,5-a]pyrimidine described in this paper is a highly regiosselective. The method is practical and simple, resulting in products with moderate to good yields.

\section{ACKNOWLEDGEMENTS}

The authors are grateful to Conselho Nacional de Desenvolvimento Científico e Tecnológico (CNPq), Fundação de Amparo à Pesquisa do Estado do Rio Grande do Sul (FAPERGS) and CAPES for financial support and fellowships. \footnotetext{
REFERENCES

${ }^{1}$ Chen, Q.; Zhu. X.; Jiang, L.; Liu, Z.; Yang, G. Europ. J. Med. Chem. 2008 43,595

${ }^{2}$ Chen,C.-N.; Chen, Q.; Liu, Y.-C.; Zhu, X.-L.; Niu, C.-W.; Xi, Z.; Yang, G.-

F. Bioorg. Med. Chem. 2010, 18, 4897.

${ }^{3}$ Battaglia, U.; Moody; C. J. J. Nat. Prod. 2010, 73, 1938

${ }^{4}$ Salgado, A.; Varela, C.; Collazo, A. M. G.; Garcia, F.; Pevarello, P.; Alkorta, I.; Elguero, J. J. Mol. Struct. 2011, 987, 13.

${ }_{5}$ Petrich, S. A.; Qian, Z.; Santiago, L. M.; Gupton, J. T.; Sikorski, A. Tetrahedron 1994, 42, 13.

${ }^{6}$ Sarah; A., Mohamed E.; El-Din, H. Salah A. M. J. Heterocyc. Chem. 2004 $41,267$.
} 